\title{
A literature review about usability evaluation methods for e-learning platforms
}

\author{
Freire, Luciana Lopes ${ }^{\mathrm{a}}$, Arezes, Pedro Miguel ${ }^{\mathrm{b}}$ and Campos, José Creissac ${ }^{\mathrm{c}}$ \\ ${ }^{a b}$ Deparment of Production and Systems Engineering - University of Minho - Guimarães, Portugal - \\ ${ }^{c}$ Deparment of Computer Science - Gualtar - University of Minho - Gualtar, Portugal -
}

\begin{abstract}
The usability analysis of information systems has been the target of several research studies over the past thirty years. These studies have highlighted a great diversity of points of view, including researchers from different scientific areas such as Ergonomics, Computer Science, Design and Education. Within the domain of information ergonomics, the study of tools and methods used for usability evaluation dedicated to E-learning presents evidence that there is a continuous and dynamic evolution of E-learning systems, in many different contexts -academics and corporative. These systems, also known as LMS (Learning Management Systems), can be classified according to their educational goals and their technological features. However, in these systems the usability issues are related with the relationship/interactions between user and system in the user's context. This review is a synthesis of research project about Information Ergonomics and embraces three dimensions, namely the methods, models and frameworks that have been applied to evaluate LMS. The study also includes the main usability criteria and heuristics used. The obtained results show a notorious change in the paradigms of usability, with which it will be possible to discuss about the studies carried out by different researchers that were focused on usability ergonomic principles aimed at E-learning.
\end{abstract}

Keywords: usability evaluation, e-learning systems, interactions of user's context.

\section{Introduction}

E-learning systems have evolved in a complex way in terms of educational contents, technological resources and interaction possibilities that might be offered through platforms like Moodle, Blackboard, among many others.

In this perspective there is an increasing concern in regard to the quality of the interface and the ways in which tasks are completed in these systems, from the view of the exact sciences as well as from the humanities, as observed in studies of [1] and [2].

However, it is known that the analysis of the use of these systems has to be reconsidered, for the usability of interfaces should be evaluated in a way that contemplates the nature of the interactions during the process of carrying out tasks.

This issue has been the subject of researches that propose a multidisciplinary approach on the same points in question. These are: (i) The manner in which the systems interface has contributed to their educational objectives; (ii) The system usability as a possible obstacle to users that seek to develop knowledge and fail their goals.

To answer these questions from the viewpoint of Ergonomics, we can observe since the eighties, researches of usability evaluation have been discussed together with other fields and sub-fields such as Participatory Design (PD), User-centered Design (UCD), Interaction Design (IxD) and analysis of the UserExperience (UX), according to [3], [4] and [5], among other authors.

"Corresponding authors: lucianafreire@gmail.com, parezes@dps.uminho.pt jose.campos@di.uminho.pt 


\section{Usability on E-learning systems}

\subsection{Definitions in the view point of ergonomics}

The definitions of Usability and E-learning vary according to the area in which they are being studied, such as Education or Engineering, for example. In general, in the view point of Ergonomics, Usability is understood to be the capacity a system has to offer to the user in carrying out of his tasks, in an effective, efficient and satisfactory manner.

This definition of usability takes on other terminologies, when usability is researched in a multidisciplinary manner, for it will be evaluated by criteria and methods that originated in fields such as Psychology and Computer Science, according to [6], [1] and [7].

So too can the definition of E-learning take on different meanings, due to the technology of the system and the possibilities of interaction offered by it. Generally these systems are known as LMSs, or Learning Management Systems.

For this paper, E-learning or LMSs are understood to be every system capable of storing, managing or modifying educational content, by interaction between the participants in the system, through their authorization to insert, alter or delete data.

This definition of e-learning is based in concepts proposed in studies within the fields mentioned before, as can be confirmed in the publications of [4], [8], [9], [10] and [11].

\subsection{Why study the usability of LMSs systems?}

The area of Human Engineering, especially Ergonomics, seeks to dedicate itself to the analysis of systems with the main focus on users. For this researchers need to join knowledge that overtakes synthetic conclusions; conclusions based on an analysis where only "success" or "failure" of a task is detected.

In this sense, it becomes indispensable to study Elearning from the perspective of Ergonomics due to the fact that these systems must contemplate, primarily, the principles of Informational Ergonomics, as presented by [12], [13] and [14]. However, also observed are the guidelines that came from Cognitive Ergonomics and Human-Computer Interaction (HCI), for these two sub areas of Ergonomics complete each other in the directives for a better usability of a system.

It should be noted that the area of HCI is understood as part of Informational Ergonomics, but in the fields of Engineering and Computer Science the area of HCI is recognized as a big area, considering the importance of the interactions occurring between users and system.

In the same way, according to the nature of Elearning systems, Education relies on Ergonomics to seek to develop better interfaces for the content presented in their systems, as claimed by [15] and [14].

Such systems are different in relation to general systems because their objective is that the user learns new knowledge through them, however many times they demand that the user has to learn to use the system so that he may attempt to fulfill the initial objective. The problem is that there is a greater concern with the educational content and system functionalities than with a concern with the interface where such content will be presented. Yet all of these aspects are connected, as an issue of functional usability, as stated by Hertzum[X] when explaining "classifications" that usability takes on, in accordance with the type of content and the characteristics and limitations of users.

Therefore, the study of E-learning, considering only the view of one field of research, in an isolated way is no longer conceived. Only with complementary knowledge can more significant evaluations be made for the redesign of interfaces, as observed by [16], [8], [9] and [17].

\section{The principal problems identified in E-learning}

General researches on usability in E-learning can identify problems of a more operational nature; for example: "objective achieved" or "objective not achieved". Classes of problems are already recognized by authors such as [18], [19], [3] , [12], [20] and [21].

As for more pertinent criteria for the analysis of Elearning interfaces, the Informational Ergonomics can point to some of the main problems, described by various authors as common problems in E-learning systems (academic or corporate), as dealt with by as dealt with by [22], [10], [23] and [24]:

\subsection{Interface problems}

Problems that occur regarding the visual and pictorial language of interfaces, also known as verbalpictorial language. The use of terms/expressions and images that create doubt about procedures, or cogni- 
tive overload, are explained by Ergonomics as dialog problems between user and system, for each element of the interface must be understood for the user to take decisions. [3, 12, 25].

\subsection{Browsing problems}

When the browsing of the system is presented in an inconsistent manner and forces the user to make unnecessary paths, you then have a browsing problem. [3], [12] and [15] also cite this problem in their heuristics and "golden rules".

\subsection{Content problems}

These problems are consolidated in the way information is presented to users. The same information, as for example, a task flowchart, might be presented in a confusing manner as to the sequence of activities described. As such, a content problem might create a usability problem, as those foreseen well before by [25], [26] and [31].

\subsection{Interaction problems}

As for interaction between users and systems, it is possible to identify that some systems do not offer the possibility of forums and chats so that users might exchange knowledge. Or offer these interaction spaces in a limited way and this affects user motivation. An E-learning system should allow and encourage interactions through all means available.

\subsection{Usability problems}

Usability problems in E-learning are similar to usability problems in systems of a different nature (eg: Compatibility, Consistency, Feedback, Error management and Satisfaction). However in Elearning, problems such as "feedback" become more complex because they involve also issues related to cultural and sociological factors, as in the analysis done by [6] and [11].

\section{Methodology for analysis of literature review}

After conducting a review of the literature of the relations between Ergonomics and usability in Elearning, we sought to select the studies that presented more integration of methods and user profiles. To then reflect and discuss the ways of evaluating that have been adopted and the new criteria that were rethought in the evaluations.

In this manner it becomes necessary from the outset to present the differences in the ways of evaluating that were identified. As well as to point out some of the methods (tools) that were presented in coherence with the new criteria and heuristics that include factors such as motivation, engagement and interaction between users.

This discussion reflects a change of paradigm where a tendency to integrate - in the same evaluation - methods of usability evaluation and also different user profiles. Besides this observation about the paradigm, also identified was a greater value being given to remote evaluation, based on synchronous and asynchronous data.

However, before this discussion about methods, it is appropriate to clarify, even if quickly, the similarities and differences between E-learning systems.

\subsection{Similarities and differences in e-learning systems}

The main point in common to most E-learning systems, like Moodle and Blackboard for example, is that they offer basic tools to store educational content. These are: virtual shelves (text and presentations deposits), chats, forums, identification board for students and teachers, notice board and emails.

As for the main difference between systems, there are those that are open source and those that are closed source. In other words: those that are open such as Moodle, allow their data management structure to be modified by the users, according to their needs.

The closed source systems, like Blackboard, may only be modified by developers and not by users the Stakeholders (end users of the system, or those directly affected).

\subsection{Main methods for evaluations on E-learning}

Among the main methods developed by the researchers already cited, those that stand out in this section are the ones where the change of paradigm mentioned is more notable. The search for the integration of different methods and different user profiles may be found in studies like those of [8], [27], [28], [29] and [30]. 
In these studies, the authors gather methods like checklists and usability tests, together with new criteria originated from Ergonomics, Education and Computer Science, as for example, user motivation and engagement. Briefly, motivation interferes in the way with which the user desires to explore more the contents and resources of the system; While engagement concerns the way in which participants interact and promote the participation of other participants. Following that, they submit the systems to evaluations carried out by stakeholders - like students and teachers, among other users of the systems evaluated in their analysis. An additional point is that methods, as systematic observations and usability tests, almost always are done in modules so that the results are completed focused on the profile of the users.

\subsection{Main criteria for evaluation in E-learning}

The criteria adopted in E-learning evaluations originated in criteria already researched by Informational Ergonomics. However more recent studies added new criteria divided in educational, communicational or multidimensional modules, as reported by [29] and [27]. These are:

Usability of the web (hypermedia connections), student preferences (users), content learning, integration of technologies, language features, proactivity of applications, incentive of interactions, among others.

The main point is that all of them start from the perspective of the user, not anymore of the system. That is: several stakeholders will explain in which aspects the system favors the accomplishment of their tasks and the way it encourages development of new knowledge, through the interaction with different profiles.

\section{Analysis and discussion about the paradigm change of the usability evaluations on E-learning}

Dozens of methods and techniques exist to evaluate usability in E-learning, but in general they establish formal divisions to analyze the object under examination, as observed in the researches of [16], [8], [10], [13], [11], [23], [6] and [9].

In time, for this article the methods and techniques may not be explained in detail, however it is considered pertinent to address three main differences among them: (i) system performance evaluation, (ii) of user performance and (iii) the evaluations of the dialogs between users and systems.

\subsection{Focus in the system's performance}

The greater part of the methods used to evaluate usability in E-learning are the same methods used for general systems - non educational. So they apply checklists, heuristics evaluations and norm inspections, in order to discover if the system fulfills or not the minimum requisites to function without creating constraints.

\subsection{Focus in the user's performance}

Regarding the methods directed towards user performance, there are "adaptations" of already consolidated evaluation methods, such as the usability tests associated with semi-structured questionnaires and interviews. Though the language of the questions applied to users is reconstructed (rethought) to be compatible with the background of those that will evaluate the E-learning system.

\subsection{Focus in the dialogues between users and system}

There are also the methods that seek multidisciplinary evaluations, where a "mix" (fusion) between methods, techniques and methodologies originated in the fields of Participatory Design, Interaction Design and User-Centered-Design is observed. These methods, such as Cognitive Walkthrough, or Systematic direct observations, must be oriented to the educational and socio-cultural aspects of the system in relation to the socio-cultural profiles of their users.

\section{Results convergent to integration of evaluations}

Based on these studies, the integration of methods already has shown to be the best option and in the defense of this argument there already exist integrated methods being applied, as pointed out by [11] and [27]. The positive points may be summarized in three main issues: (i) The best identification of system problems; (ii) the possibility of realizing quick and less costly evaluations; (iii) the best way to analyze the synchronous and asynchronous data.

\subsection{Better identification of problems in E-learning}

As a system is evaluated and revaluated by many user profiles, the mistakes that are of lesser importance to some, might present themselves as determining factors to the conclusion of tasks for others. This 
happens because, even though the evaluation criteria are the same in the majority of methods, the analysis perspective of a teacher might be completely different from the analysis perspective of a student. Motivations and "Engagement" with the task tends to vary with the use made of the system and the knowledge obtained through it.

\subsection{Better costs and benefits on remote evaluations}

The results obtained in the studies mentioned indicate that the cost of usability evaluations may be reduced if the researcher is able to carry out all tasks (or part of them) through online tools. Integrating methods and tools allows the researcher to conduct parallel tests. For example: while he carries out interviews and after that a focus group online, other participants (with the same or different profile) may be applying checklists and/or heuristics evaluations, for less time is demanded in all stages of the evaluation.

Taking into account that Ergonomics defends being closer to the user so as to observe better the way in which he performs his activities, yet, with the new technologies, it is possible to track the activities without the need for participants to travel.

The proposals for method integration do not state that one method is better than another, nor do they say that qualitative methods are better than quantitative. What is instructed is the combination of the best evaluation instruments in detriment of techniques that demand more time and/or greater financial cost, in this process.

\subsection{Better view of data (synchronous/asynchronous)}

Finally, it should be explained that when integrating methods it is possible to conduct better the evaluation stages and in this manner, observe if there was a variation of results when the interactions were synchronous or asynchronous.

For example: if a teacher proposes a discussion in a chat and the students respond in real time, the researcher may evaluate in which way they use system resources to contribute with the chat discussion. Or if a student posts a question in the forum and waits for others to respond, the researcher may evaluate the response time for this type of asynchronous interaction.

He could also seek to interpret if when using the same space in the system - a notice board for example - if interactions are conditioned to be more continuous when the subject of the notices is information accompanied with links, images or other audiovisual resources. Based on this context the possibilities of analysis tend to be as significant as those usability evaluations realized in loco.

\section{Conclusion}

The studies on usability have already evolved considerably in the last 30 years, yet it is necessary to direct the new researches to forms of evaluation that are more complete and quicker. In this sense, not only is the integration of methods and stakeholders important, but also the viability of these proposed integrations.

Although it is defended that the evaluations must start as soon as possible in system projects, the logic of system production - be they sites or software - is conducted by market standards, where many times it is more profitable to launch quickly an "almost perfect" system rather than invest more time and money in a "possibly perfect" system. In contrast to this logic of action, investigators insist increasingly more on the importance of knowing how to evaluate these systems, by proving that this conduct brings financial returns and avoids "re-working" to correct the primary mistakes in the systems.

In order to summarize the main discoveries of this review on evaluation methods of E-learning, the more relevant characteristics of the studies cited in the body of this article should be pointed out:

- For [4], [7], [1] and [15], usability in E-learning is directly related to the interaction possibilities among participants.

- For [9], [5] and [28], usability is always something functional, that is: it is qualified depending on the objective of the system and the profile of the users. - For [8], [11] and [23], the methods must complement one another for a better evaluation, for there exist criteria that are more operational, others completely subjective (like satisfaction) and also, the communicational, from the observed interactions.

- For [30], [27], [10], [24], [29] and [22], new multidisciplinary methods need to be created, for even with adaptations in consolidated methods, it is still necessary to "give more voice" to users, so that their opinions become requisites for the redesign of systems.

- For [14], [17] and [2], there exist conditions for evaluations of a more qualitative nature to be rethought, so as to integrate different evaluation me- 
thods with different user profiles, without comparing, but to add more value to the sum of the obtained results.

- For [13], [16] and other authors, the studies point to the possibilities of carrying out evaluations at a distance, just as there has been success in Distance Education, because a differentiated "disposition" of the participants involved can be observed.

There are usability evaluations being done completely virtual (online); the so called remote evaluations. With the current technology available it has become ever more relevant to think about converging tools common in the life of users (such as emails and instant messages) so that they might provide quicker feedback about the systems.

Independently of the tools used to join users, the most important point is knowing how to join (mix) the most pertinent methods to each kind of evaluation and to each profile of Stakeholder. Knowing that Ergonomics is careful to respect the characteristics and limitations of users of every system, it is necessary that the methods applied in ergonomic analysis and usability evaluations be the first to obey such a premise.

\section{Acknowledgments}

These are due to the supervisors of and participants in the research; to University of Minho, ERASMUS.

\section{References}

[1] Aalbert, B., Tullis, T. \& Tedesco, D. (2010). Beyond the usability lab: Conducting Large-scale On-line User Experience Study. Morgan Kaufmann, Burlington, MA, USA.

[2] Litto, F. M. \& Formiga, M. (2009). Educação a distância: o estado da arte. São Paulo, Pearson Education.

[3] Nielsen, J. (1993). Usability Engineering. San Diego, Academic Press.

[4] Preece, J. (2000). Online Communities: Designing Usability, Supporting Sociability. Chichester, UK: John Wiley \& Sons.

[5] Hollingsed, T. \& Novick, D.G. (2007). Usability inspection methods after 15 years of research and practice. In: SIGDOC, Texas, USA.

[6] Hertzum, M. (2010). Images of Usability. In: Proceedings of International Journal of Human-Computer Interaction, V. 26: 6, pp. $567-600$

[7] Preece, J.; Rogers, Y. \& Sharp, H. (2005). Design de interação: Além da interação homem-computador. Porto Alegre: Bookman.

[8] Ardito C., DE Marsico M., Lanzilotti R., Levialdi S., Roselli T., Rossano V. \& Tersigni M. (2004). Usability of E-Learning Tools. In: Proceedings of International Conference on Advanced Visual Interface (AVI), Gallipoli, Italy, V. May 25-28, pp. 80-84, ACM Press, NY.
[9] Zaharias P. (2004). Usability and E-Learning: The road towards integration. ACM eLearn Magazine, 2004.

[10] Granic, A. (2008). Experience With Usability Evaluation of ELearning Systems. In: Universal Access in the Information Society, pp.209-221.

[11]Federici S, \& Borsci S. (2011). Usability Evaluation: Models, Methods, and Applications. In: JH Stone, M Blouin, editors. International Encyclopedia of Rehabilitation. Available at: www.cirrie.buffalo.edu/encyclopedia/en/article/ Consultado em 14/07/11

[12] Shneiderman, B. (1992). Designing The User Interface: Strategies For Effective Human- Computer Interaction. Reading, Addison-Wesley.

[13]Costabile, M.F. (2005) On the Usability Evaluation of ELearning Applications. In: Proceedings of the 38th Annual Hawaii International Conference on System Sciences, HICSS.

[14]Freire, L., Arezes, P.M., Creissac, J. (2010). Princípios de Ergonomia e Usabilidades aplicados a plataformas de Elearning com o objectivo de minimizar possíveis sobrecargas cognitivas dos utilizadores, in Arezes, P., Baptista, J.S., Barroso, M.P., Carneiro, P., Cordeiro, P., Costa, N., Melo, R., Miguel, A.S., Perestrelo, G.P. (Eds.). Occupational Safety and Hygiene - SHO 2010, pp 256-260.

[15]Tullis, T.; Albert, W. (2008). Measuring the User Experience: Collecting, Analyzing, and Presenting Usability Metrics. Margan Kaufmann.

[16]Blecken, A., Bruggemann, D., \& Marx, W. (2010) Usability Evaluation of a Learning Management System. In: Proceedings of $43^{\circ}$ HICSS. IEEE, pp. 1-9.

[17]Cavus, N. \& Momani, A. M. (2009). Computer Aided Evaluation of Learning Management Systems. In: Proceedings of Social and Behavioral Sciences, V.1, pp. 426-430.

[18]Chapins, A. (1991). Evaluating usability. In Shackel, B. e RichardsonI, S. eds. Human factors for informatics usability. Cambridge, Cambridge University Press. p. 359-395

[19]Rubin, J. (1994). Handbook of usability testing: how to plan, design, and conduct effective tests. NY, John Wiley \& Sons.

[20] Joedon, P. W. (1998). An Introduction to usability. London, Taylor \& Francis.

[21]Norman, D. A. (2002). The Design Of Everyday Things. San Diego, Basic Books.

[22]Semugabi, S. \& De Villiers, M.R. (2007). Usability and Learning: A Framework for Evaluation of Web-Based ELearning Applications. In: Proceedings of the ED-MEDIA World Conference on Educational Multimedia, Hypermedia \& Telecommunications, pp. 906-913. Vancouver, Canada.

[23]Kock, E., Bojon, J. V., \& Petrorius, M., (2009). Usability evaluation methods: minds the gaps. In: SaicsitA, South Africa.

[24]Lanzilotti R., Ardito C., Costabile M. F., DE Angeli A. (2010). Do patterns help novice evaluators? A comparative study. In: International journal of human computer studies, V.69 (1-2), pp. 52-69

[25] Maguire, M. (2001). Methods to support human-centred design. International Journal of Human-Computer Studies, V.55, p. $587-634$.

[26]Hom, J. (2003) Usability Methods Toolbox. Availabe at: www.jthom.best.vwh.net/usability. Consulted in 12/03/2010

[27]Liu G., Liu Z. \& Hwang, G. (2011). Developing multidimensional evaluation criteria for English learning websites with university students and professor. Published in: · Journal Computers \& Education. V. 56 Issue 1, January, 2011. Elsevier Science Ltd. Oxford, UK.

[28]Zaharias, P. \& Polymenarou, A. (2009). Developing a Usability Evaluation Method for E-Learning Applications: Beyond Functional Usability. Proceedings of International Journal of Human-Computer Interaction, V. 25, pp. 75-79. 
[29] Oztekin, A., Kong, Z. \& Uysal, O., (2010). UseLearn: A Novel Checklist and Usability Evaluation Method for eLearning Systems by Criticality Metric Analysis," International Journal of Industrial Ergonomics, V. 40, N.4, pp. 455-469.

[30]Al-Wabil, A. \& Al-Khalifa, H., (2009). A Framework for Integrating Usability Evaluations Methods: The Mawhiba Web Portal Case Study. In: Proceedings of International conference on the Current Trends in Information Technology (CTIT'09), Dubai, UAE.

[31]Bastien, C. \& Scapin, D. (1993). Ergonomic Criteria For The Evaluation Of Human-Computer Interfaces. Inria, Rapport Technique. 